Broman-Fulks, J. J., Ruggiero, K. J., Hanson, R. F., Smith, D. W., Resnick, H. S., Kilpatrick, D. G., \& Saunders, B. S. (2007). Sexual assault disclosure in relation to adolescent mental health: Results from the National Survey of Adolescents. Journal of Clinical Child and Adolescent Psychology, 36(2): 260-266. (Apr 2007) Published by Taylor \& Francis (ISSN: 1537-4424). DOI: 10.1080/15374410701279701

\title{
Sexual Assault Disclosure in Relation to Adolescent Mental Health: Results From the National Survey of Adolescents
}

Joshua J. Broman-Fulks, Kenneth J. Ruggiero, Rochelle F. Hanson, Daniel W. Smith, Heidi S. Resnick, Dean G. Kilpatrick, and Benjamin E. Saunders

\begin{abstract}
Child sexual assault is a risk factor for a wide range of emotional and behavioral problems. Little is known about mental health functioning in relation to victims' decisions to tell someone (or not) about their assault. This study used data from a nationally representative sample of 4,023 adolescents to examine the relation between sexual assault disclosure characteristics and mental health outcomes. Results indicated that youth who disclosed the assault to someone within 1 month were at reduced risk for current major depressive episode (MDE) and delinquency. No relation was found between disclosure latency and risk for posttraumatic stress disorder (PTSD) or substance use problems. Notably, disclosure to mothers was associated with significantly reduced risk for current PTSD and delinquency.
\end{abstract}


Child sexual assault (i.e., forcible sexual contact with a child) is a serious public health problem and risk factor for psychosocial impairment and health-risk behavior (Kilpatrick et al., 2003; Saunders, Kilpatrick, Hanson, Resnick, \& Walker, 1999). Several studies have examined the epidemiology of sexual assault and assault-related mental health, but limited data address modifiable postassault variables, such as parental support, receipt of evidence-based services, and whether the child disclosed the assault to a trusted adult, that may inform the development of intervention and secondary prevention protocols. Although the roles of parental support and evidence-based services in the postassault recovery of youth have received increased attention in recent years, little is known about youth disclosure of sexual assault in relation to later psychosocial outcomes.

Studies with representative samples estimate that nearly one in three sexual assault victims never disclose their assault to another person and at least two in three never report the assault to social services or law enforcement (Hanson et al., 2003; Hanson, Resnick, Saunders, Kilpatrick, \& Best et al., 1999; Smith et al., 2000). Further, there is wide variability in the timing and context of disclosure. Many disclosers wait weeks, months, or years before they tell someone about their sexual assault. Some only tell their caregivers or a close friend, some disclose only to helping professionals, and still others disclose to numerous sources. Whether, when, and whom sexual assault victims choose to disclose may have important implications for postassault recovery.

Limited data are available to address key questions concerning the role of disclosure in postassault youth functioning and published studies to date have yielded mixed results (see Ruggiero et al., 2004, for a review). Briefly, studies have found (a) no psychosocial differences between disclosers and nondisclosers in adult samples but inconsistent results in child samples, (b) lower risk for posttraumatic stress disorder (PTSD) among persons who disclosed within 1 month of the incident (vs. nondisclosers and delayed disclosers) in two studies but no relation between mental health and timing of disclosure in two others, and (c) disclosing to mothers (vs. other confidants) was related to greater psychosocial well-being in one 
study of youth but not in a second study of adults. Methodological issues likely have contributed to these inconsistencies in the data. For example, most studies have relied on the use of samples with limited external validity (e.g., college students, clinic-based), long-term retrospective recall, assessment of different psychosocial constructs across studies (e.g., self-esteem vs. PTSD), and small samples. Ruggiero et al. (2004) conducted the first population-based study on child sexual assault disclosure in relation to adult psychosocial functioning (n 1/4 3,220, 288 of whom were forcibly raped in childhood). Results were that (a) prevalence of past-year PTSD and depression was higher for women who had waited at least 1 month to disclose compared to nondisclosers and immediate disclosers, (b) past-year substance abuse was unrelated to the occurrence and timing of disclosure, (c) delayed disclosure in childhood was associated with adult PTSD after controlling key risk factors, and (d) disclosure to mothers was unrelated to adult mental health and health-risk behavior. Due to the length of time between the sexual assault and the past-year problems in adulthood (mean age of participants was 45 years), these data tell us little about relatively shorter term correlates of disclosure.

The National Survey of Adolescents (NSA), a study of 4,023 adolescents ages 12 to 17 years, presents a unique opportunity to address these concerns and advance this literature toward the goal of informing secondary prevention. First, similar to the study with a national sample of adult women (Ruggiero et al., 2004), the NSA addresses several limitations that are pervasive in the literature (e.g., overreliance on convenience samples, statistical power issues). Second, the interval between sexual assault and current psychosocial functioning is considerably shortened, thus reducing potential limitations in recall. Third, this is the first study conducted with a population-based sample of youth to examine sexual assault disclosure in relation to psychosocial outcomes.

Fourth, the NSA included both boys and girls and assessed several clinical constructs. Based on our previous research and review of the literature, we hypothesized that youth who disclosed the assault soon after the initial incident (i.e., within 1 month) would have a lower prevalence of PTSD, 
depression, substance abuse, and delinquency. Also, based on the findings of previous studies indicating that mothers tend to respond to CSA disclosure with supportive responses and that higher levels of social support following a traumatic event are associated with better psychosocial outcomes, we hypothesized that adolescents who disclosed first to their mother would have less psychosocial impairment than those who did not disclose to mothers.

\section{METHOD}

\section{Participants}

Participants were a national household probability sample of 3,161 adolescents and an oversample of 862 inner-city adolescents. Sample selection and interviewing were conducted using a multistage, stratified, area probability random digit dial procedure. Data were weighted to the general population on the basis of geographic stratum, age, gender, and race=ethnicity to correct for oversampling. Of those who provided complete interview data (n 1/4 3906), 321 reported a history of sexual assault (8.2\%): 251 girls (78\%) and 70 boys (22\%), with a mean age of 15.2 years (SD $1 / 4$ 1.6). All analyses were conducted on this subsample of 321 participants. Two participants were dropped from analyses due to missing disclosure data.

\section{Procedures}

Kilpatrick, Acierno, Resnick, Saunders, and Best (2000) and Kilpatrick et al. (2003) provided further details about the NSA sample and methodology. All variables were obtained from a highly structured interview was administered to participants by telephone.

The interview was about 35 min in length and was administered by trained interviewers. A computer-assisted telephone interview system prompted interviewers with each question on a computer screen; supervisors conducted random checks of data entry accuracy and interviewers' adherence. Participants and their parents consented verbally via telephone. Several steps were 
taken to ensure privacy and integrity of the data (refer to Kilpatrick et al., 2000, for detailed procedural information). All study procedures were approved by Medical University of South Carolina's Institutional Review Board.

\section{Measures}

Sexual assault history, assessed using a series of behaviorally specific questions (see Kilpatrick et al., 2003), was defined as forced (a) vaginal or anal penetration by an object, finger, or penis; (b) oral-genital contact; (c) touching of the respondent's breasts or genitalia; or (d) respondents' touching of another person's genitalia.

Disclosure was assessed for participants who endorsed sexual assault: "Did you ever tell anyone about this (these) incident(s)?" Participants who responded affirmatively to this question were asked two follow-up questions: "How long after the incident did you first tell someone about it?" and "Who did you tell first?"

PTSD was assessed using a modified version of the NationalWomen's Study PTSDModule (Kilpatrick, Resnick, Saunders, \& Best, 1989), which assessed each Diagnostic and Statistical Manual of Mental Disorders (fourth edition; American Psychiatric Association, 1994) criterion with a yes $=$ no response for the 6-month period prior to interview. Data support the construct validity, temporal stability, reliability of administration and diagnosis, and other psychometrics of the National Women's Study-PTSD (e.g., Kilpatrick et al., 1998; Ruggiero, Rheingold, Resnick, Kilpatrick, \& Galea, in press). Major depressive episode (MDE) was assessed using the National Women's Study Depression Module that targeted MDE criteria using a yes=no no format for each Diagnostic and Statistical Manual of Mental Disorders (fourth edition; American Psychiatric Association, 1994) symptom during the 6-month period prior to the interview. Psychometrics (e.g., internal consistency, convergent validity) were well supported for this module (e.g., Kilpatrick et al., 2003).

Past-year substance abuse $=$ dependence $(S A=D)$ was assessed across a range of substances following Diagnostic and Statistical Manual of Mental 
Disorders (fourth edition) criteria (see Kilpatrick et al., 2000). SA=D was operationalized as the presence of either substance abuse or dependence. Past-year delinquency was assessed using a slightly modified version of a scale used by Elliott, Huizinga, and Ageton (1985) in the National Youth Study. Delinquency was operationalized as one or more Crime Index offense as defined by the FBI Uniform Crime Reports (e.g., stealing, breaking and entering, physically assaulting someone).

\section{RESULTS}

Disclosure data were obtained from 319 adolescents who endorsed a history of sexual assault, 206 (65.8\%) of whom reported a single incident (vs. series of incidents). Mean age of onset was 11.2 years $(\mathrm{SD}=3.8)$, consistent with prior population-based studies (Ruggiero et al., 2006; Saunders et al., 1999). Perpetrators were nonrelatives in 243 (77.8\%) cases. Most $(n=195,60.6 \%)$ reported that the perpetrator used force or verbal threats in the context of the assault, and $33(10.4 \%)$ incurred injuries. Nearly one third $(n=101$, $31.7 \%$ ) had not disclosed the sexual assault prior to interview (i.e., nondisclosers). The remaining 218 reported that they had previously disclosed to someone; 127 (39.8\%) told someone within 1 month of the incident (i.e., short-delay disclosers), and 91 (28.6\%) waited longer than 1 month (i.e., long-delay disclosers). Data were missing for $23 \%$ who could not recall disclosure latencies.

\section{Disclosure and Psychosocial Functioning}

Bivariate analyses. Chi-square analyses were used to examine disclosure in relation to PTSD, MDE, SA=D, and delinquency. Past 6 months prevalence of PTSD did not differ between shortdelay (22\%), long-delay (13\%), and nondisclosers $(24 \%), X 2(2, n=319)=3.86, p>.10$. In contrast, long-delay disclosers had a higher prevalence of past 6 months MDE (37\%) than short-delay (23\%) and nondisclosers (26\%), X2(2, $\mathrm{n}=319)=5.90, \mathrm{p}<.05$. Past-year SA=D did not differ across groups (26\% short-delay, 20\% longdelay, $22 \%$ nondiscloser), $X 2(2, n=319)=1.26$, 
$p>$.10. Finally, the prevalence of past-year delinquency was higher among nondisclosers (30\%) than long-delay disclosers (12\%) and shortdelay disclosers $(20 \%), X 2(2, n=318)=9.14$, $p<.01$.

Multivariable regression analyses. Hierarchical logistic regressions were conducted for MDE and delinquency with demographics entered on the first level, assault variables on the second level, and disclosure variables on the final level. In the final model for MDE (Table 1), long-delay disclosure (odds ratio $[O R]=2.43$ vs. short-delay) remained associated with past 6 months MDE. Household income was the only other variable associated with MDE in the final model. For past-year delinquency (Table 2), female gender (OR $=0.30$ vs. boys), single-incident assault (OR $=0.44$ vs. series of assaults), and having a familial perpetrator (OR $=0.22$ vs. nonfamilial perpetrator) all were associated with reduced risk. Nondisclosers were at greater risk of delinquency than short-delay disclosers $(\mathrm{OR}=2.30)$.

Table 1. Demographics, Sexual Assault Characteristics, and Disclosure in Relation to Past 6-Months MDE

\begin{tabular}{|c|c|c|c|c|c|c|c|c|c|c|}
\hline \multirow[b]{2}{*}{ Risk Factor } & \multicolumn{5}{|c|}{ Step } & \multicolumn{5}{|c|}{ Final Model } \\
\hline & $B$ & SE & Wald & OR & CI $(95 \%)$ & $B$ & SE & Wald & OR & CI $(95 \%)$ \\
\hline \multicolumn{11}{|l|}{ Step 1} \\
\hline Current age & 0.06 & 0.09 & 0.43 & 1.06 & $0.89-1.28$ & 0.01 & 0.10 & 0.01 & 1.01 & $0.83-1.23$ \\
\hline Income $>\$ 10,000$ & 1.12 & 0.52 & $4.69^{*}$ & 3.05 & $1.11-8.37$ & 1.25 & 0.53 & $5.54^{*}$ & 3.48 & $1.23-9.85$ \\
\hline White & 0.14 & 0.49 & 0.08 & 1.15 & $0.44-3.02$ & 0.02 & 0.52 & 0.00 & 1.02 & $0.37-2.83$ \\
\hline African American & -0.88 & 0.62 & 2.03 & 0.42 & $0.12-1.39$ & -0.95 & 0.64 & 2.22 & 0.39 & $0.11-1.35$ \\
\hline Hispanic & 0.35 & 0.61 & 0.33 & 1.42 & $0.43-4.71$ & 0.16 & 0.64 & 0.06 & 1.18 & $0.33-4.14$ \\
\hline Gender & -0.28 & 0.35 & 0.63 & 0.76 & $0.39-1.50$ & -0.18 & 0.38 & 0.23 & 0.84 & $0.40-1.75$ \\
\hline \multicolumn{11}{|l|}{ Step 2} \\
\hline Age of child rape onset & 0.05 & 0.05 & 0.98 & 1.05 & $0.95-1.15$ & 0.06 & 0.05 & 1.44 & 1.06 & $0.96-1.18$ \\
\hline Single sexual assault & 0.44 & 0.34 & 1.68 & 1.55 & $0.80-3.03$ & 0.47 & 0.35 & 1.84 & 1.60 & $0.81-3.16$ \\
\hline Familial perpetrator & 0.07 & 0.43 & 0.03 & 1.08 & $0.47-2.49$ & -0.15 & 0.44 & 0.11 & 0.86 & $0.36-2.06$ \\
\hline Victim injured during rape & 0.24 & 0.45 & 0.29 & 1.28 & $0.52-3.11$ & 0.29 & 0.46 & 0.39 & 1.33 & $0.54-3.28$ \\
\hline \multicolumn{11}{|l|}{ Step 3} \\
\hline Long-delay disclosure & & & & & & 0.89 & 0.38 & $5.42^{*}$ & 2.43 & $1.15-5.13$ \\
\hline Nondisclosure & & & & & & 0.46 & 0.38 & 1.50 & 1.59 & $0.76-3.31$ \\
\hline
\end{tabular}

Note. ${ }^{a} n=319 . \mathrm{MDE}=$ major depressive episode $\mathrm{SE}=$ standard error $; \mathrm{OR}=$ odds ratio; $\mathrm{CI}=$ confidence interval. Current age and age of child rape onset are continuous variables. All others are dichotomously coded, with a value of 0 reflecting that the demographic/rape characteristic was not endorsed and a value of 1 indicating that the characteristic was endorsed. 
Table 2. Demographics, Sexual Assault Characteristics, and Disclosure in Relation to Past-Year Delinquency ${ }^{a}$

\begin{tabular}{|c|c|c|c|c|c|c|c|c|c|c|}
\hline \multirow[b]{2}{*}{ Risk Factor } & \multicolumn{5}{|c|}{ Step } & \multicolumn{5}{|c|}{ Final Model } \\
\hline & $B$ & SE & Wald & OR & CI $(95 \%)$ & $B$ & SE & Wald & OR & CI $(95 \%)$ \\
\hline \multicolumn{11}{|l|}{ Step 1} \\
\hline Current age & -0.04 & 0.10 & 0.16 & 0.96 & $0.78-1.18$ & -0.07 & 0.12 & 0.32 & 0.94 & $0.74-1.18$ \\
\hline Income $>\$ 10,000$ & 0.58 & 0.50 & 1.34 & 1.79 & $0.67-4.80$ & 0.41 & 0.51 & 0.63 & 1.50 & $0.55-4.09$ \\
\hline White & -1.02 & 0.50 & $4.23^{*}$ & 0.36 & $0.14-0.95$ & -0.87 & 0.56 & 2.38 & 0.42 & $0.14-1.26$ \\
\hline African American & -0.49 & 0.56 & 0.76 & 0.61 & $0.21-1.84$ & -0.83 & 0.62 & 1.78 & 0.44 & $0.13-1.48$ \\
\hline Hispanic & -0.29 & 0.63 & 0.21 & 0.75 & $0.22-2.58$ & -0.05 & 0.69 & 0.01 & 0.95 & $0.25-3.70$ \\
\hline Gender & -1.36 & 0.35 & $15.35^{* * *}$ & 0.26 & $0.13-0.51$ & -1.21 & 0.38 & $9.97^{* *}$ & 0.30 & $0.14-0.63$ \\
\hline \multicolumn{11}{|l|}{ Step 2} \\
\hline Age of child rape onset & 0.07 & 0.05 & 1.77 & 1.07 & $0.97-1.19$ & 0.05 & 0.06 & 0.69 & 1.05 & $0.94-1.17$ \\
\hline Single sexual assault & -0.77 & 0.37 & $4.24^{*}$ & 0.47 & $0.23-0.96$ & -0.81 & 0.38 & $4.66^{*}$ & 0.44 & $0.21-0.93$ \\
\hline Familial perpetrator & -1.39 & 0.58 & $5.72^{*}$ & 0.25 & $0.08-0.78$ & -1.50 & 0.59 & $6.39^{*}$ & 0.22 & $0.07-0.71$ \\
\hline Victim injured during rape & 0.40 & 0.51 & 0.59 & 1.49 & $0.54-4.07$ & 0.39 & 0.52 & 0.58 & 1.48 & $0.54-4.09$ \\
\hline \multicolumn{11}{|l|}{ Step 3} \\
\hline Long-delay disclosure & & & & & & 0.23 & 0.47 & 0.25 & 1.26 & $0.50-3.16$ \\
\hline Nondisclosure & & & & & & 0.83 & 0.40 & $4.39^{*}$ & 2.30 & $1.06-5.01$ \\
\hline
\end{tabular}

Note. $a_{n}=319 . \mathrm{SE}=$ standard error; $\mathrm{OR}=$ odds ratio; $\mathrm{CI}=$ confidence interval. Current age and age of child rape onset are continuous variables. All others are dichotomously coded, with a value of 0 reflecting that the demographic/rape characteristic was not endorsed and a value of 1 indicating that the characteristic was endorsed.

\section{Disclosing to Mothers Versus not Disclosing to Mothers}

Descriptive and bivariate analyses. Seventyfive adolescents (24\%) indicated that their first (or only) disclosure was to their mother, whereas $143(45 \%)$ first disclosed to someone else, and 101 (32\%) never disclosed to anyone. Figure 1 depicts the prevalence of PTSD, MDE, SA=D, and delinquency across these groups. Relative to adolescents who disclosed to other confidants and nondisclosers, those who disclosed first (or ever) to their mother had much lower prevalences of past 6 months PTSD, $7 \%$ versus $25 \%$ versus $23 \%$; $X 2$ (2, $\mathrm{n}=320)=10.79, \mathrm{p}<.01$; past-year $\mathrm{SA}=\mathrm{D}, 12 \%$ versus $29 \%$ versus $21 \%$; $X 2(2, n=320)=8.61$, $\mathrm{p}<.01$; and past-year delinquency, $9 \%$ versus $21 \%$ versus $29 \% ; \mathrm{X} 2(2, \mathrm{n}=320)=10.30, \mathrm{p}<.01$; but not past 6 months MDE, 24\% versus 31\% versus $25 \%$; $X 2(2, n=320)=1.49, p>.10$.

Multivariable regression analyses. Controlling for demographic (Level 1) and sexual assault variables (Level 2) in hierarchical logistic regressions, youth who did not disclose to mothers were more than four times as likely $(\mathrm{OR}=4.65)$ to have PTSD than those who disclosed to 
mothers (Table 3). Assault-related injury was also associated with PTSD (OR $=3.79$ vs. no injury).
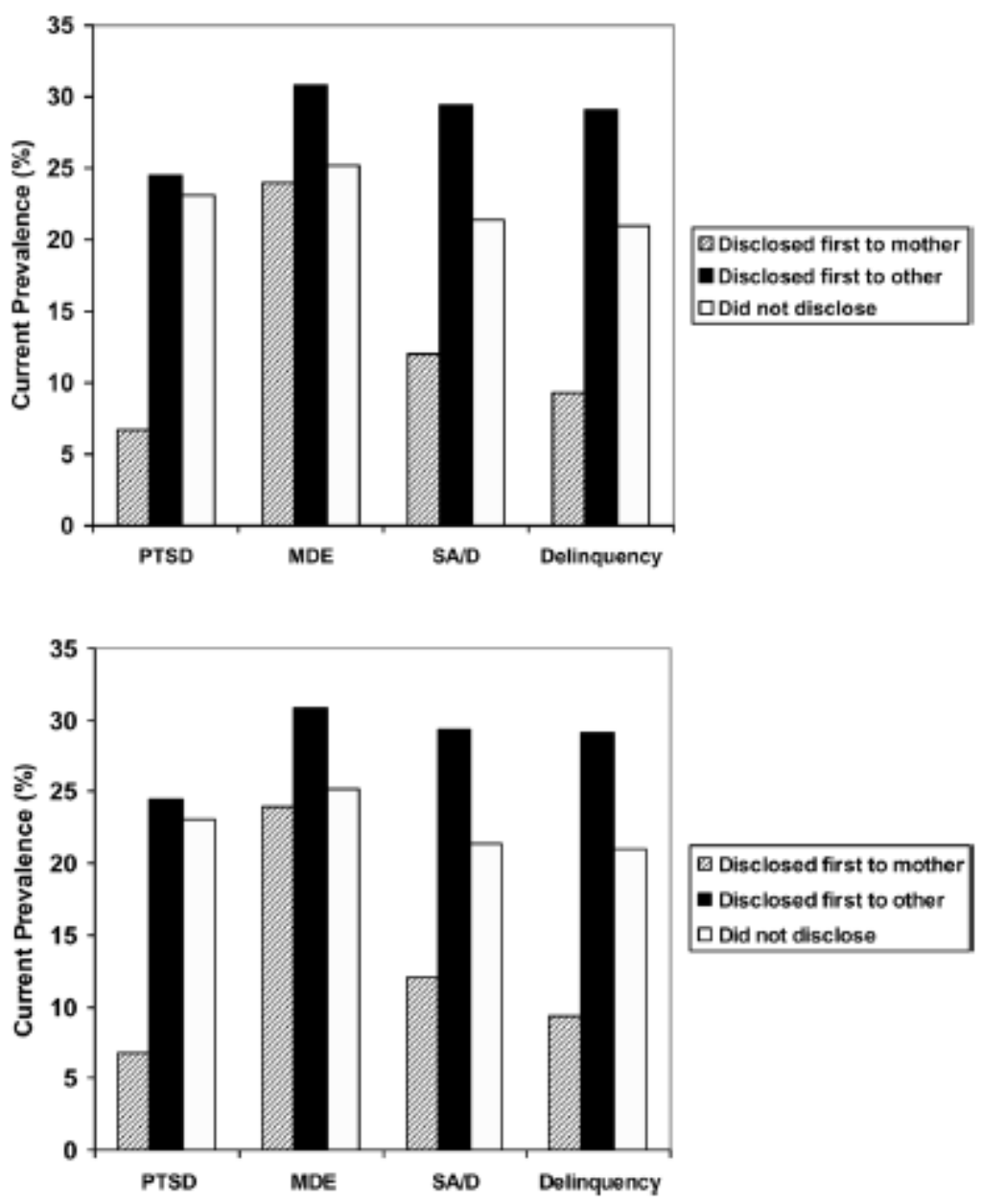

Figure 1. Prevalence of past 6 months PTSD, MDE, and past-year SA/D and delinquency among sexually assaulted adolescents who disclosed the assault first (or ever) to their mothers versus disclosing to other confidants versus never disclosing.

With regard to past-year $S A=D$, youth who

disclosed to mothers had less than half the risk of $\mathrm{SA}=\mathrm{D}$ than their counterparts $(\mathrm{OR}=.43$, $\mathrm{p}=.07$ ), but this did not reach statistical significance in the final model. African American youth had lower risk $(O R=.19)$ and older adolescents higher risk for $\mathrm{SA}=\mathrm{D}(\mathrm{OR}=1.40$ per year increase). Female youth $(\mathrm{OR}=.26)$ and youth who reported a single sexual assault incident $(\mathrm{OR}=.46)$ or familial assault $(\mathrm{OR}=.28)$ 
were at reduced risk for SA=D. Delinquency was

not associated with disclosure to mothers in the

final model.

Table 3. Demographics, Sexual Assault Characteristics, and Disclosure to Mothers in Relation to Past-Year PTSD ${ }^{a}$

\begin{tabular}{|c|c|c|c|c|c|c|c|c|c|c|}
\hline \multirow[b]{2}{*}{ Risk Factor } & \multicolumn{5}{|c|}{ Step } & \multicolumn{5}{|c|}{ Final Model } \\
\hline & $B$ & SE & Wald & OR & CI $(95 \%)$ & $B$ & SE & Wald & OR & CI $(95 \%)$ \\
\hline \multicolumn{11}{|l|}{ Step 1} \\
\hline Current age & 0.05 & 0.11 & 0.23 & 1.05 & $0.85-1.30$ & -0.06 & 0.12 & 0.25 & 0.94 & $0.75-1.19$ \\
\hline Income $>\$ 10,000$ & 1.20 & 0.65 & 3.43 & 3.31 & $0.93-11.71$ & 1.19 & 0.67 & 3.17 & 3.28 & $0.89-12.09$ \\
\hline White & 1.13 & 0.77 & 2.13 & 3.08 & $0.68-13.96$ & 1.08 & 0.82 & 1.75 & 2.95 & $0.60-14.61$ \\
\hline African American & 0.70 & 0.85 & 0.68 & 2.01 & $0.38-10.62$ & 0.33 & 0.88 & 0.14 & 1.39 & $0.25-7.85$ \\
\hline Hispanic & 1.23 & 0.87 & 2.00 & 3.44 & $0.62-19.01$ & 1.08 & 0.93 & 1.34 & 2.94 & $0.48-18.20$ \\
\hline Gender & -0.29 & 0.39 & 0.57 & 0.75 & $0.35-1.60$ & -0.31 & 0.42 & 0.56 & 0.73 & $0.33-1.66$ \\
\hline \multicolumn{11}{|l|}{ Step 2} \\
\hline Age of child rape onset & 0.15 & 0.07 & $5.43^{*}$ & 1.16 & $1.03-1.32$ & 0.11 & 0.07 & 2.81 & 1.12 & $0.98-1.28$ \\
\hline Single sexual assault & 0.12 & 0.40 & 0.08 & 1.12 & $0.51-2.47$ & 0.16 & 0.41 & 0.15 & 1.17 & $0.53-2.60$ \\
\hline Familial perpetrator & 0.12 & 0.55 & 0.04 & 1.12 & $0.38-3.31$ & 0.41 & 0.58 & 0.49 & 1.50 & $0.48-4.71$ \\
\hline Victim injured during rape & 1.21 & 0.47 & $6.73^{* *}$ & 3.36 & $1.35-8.41$ & 1.33 & 0.49 & $7.45^{* *}$ & 3.79 & $1.46-9.88$ \\
\hline \multicolumn{11}{|l|}{ Step 3} \\
\hline Disclosure to mothers & & & & & & -1.54 & 0.60 & $6.57^{* *}$ & 0.22 & $0.07-0.70$ \\
\hline
\end{tabular}

Note. ${ }^{a} n=319$. PTSD $=$ post traumatic stress disorder, $\mathrm{SE}=$ standard error; $\mathrm{OR}=$ odds ratio $\mathrm{CI}=$ confidence interval. Current age and age of child rape onset are continuous variables. All others are dichotomously coded, with a value of 0 reflecting that the demographic/rape characteristic was not endorsed and a value of 1 indicating that the characteristic was endorsed.

\section{DISCUSSION}

This study was the first study to examine mental health functioning in relation to disclosure of sexual assault in a nationally representative sample of youth. Also unique was the focus on disclosure to mothers, inclusion of SA=D and delinquency among psychosocial variables examined, and administration of structured diagnostic measures. Results have important implications for secondary prevention and future research. First, adolescents who waited longer than 1 month to disclose were more than twice as likely as short-delay disclosers to meet criteria for MDE. This relation held after controlling key variables, suggesting that risk for MDE may be associated with factors that lead children to delay their disclosures (e.g., perpetrator threats, anticipation of a nonsupportive response) or with circumstances that follow immediate versus delayed disclosures (e.g., degree of support or protection). Research is needed to better understand the decision-making process of youth around disclosure as well as how disclosure relates 
to protective or supportive actions in social networks. Such research would have important implications for public education and secondary prevention. It is unclear why disclosure was related to risk for MDE but not PTSD.

Second, nondisclosers were more than twice as likely as short-delay disclosers to have committed a delinquent offense in the past year. One interpretation is that short-delay disclosers may be more likely to get immediate help from their support network that reduces negative affect and anger-related reactions post-assault. These issues may more often go unaddressed for nondisclosers, thereby possibly increasing vulnerability to delinquency and affiliation with delinquent peers. Another potential third-variable interpretation is that nondisclosers may have weaker familial or social support systems than disclosers, which may increase hesitance to seek help or support via disclosure and may also be associated with delinquency risk. These alternative interpretations could not be tested.

Third, a striking finding was that disclosure to mothers was associated with nearly five times lower risk of youth who did not disclose first to their mothers. Based on other population-based studies, it is likely that in the majority of cases disclosure to mothers was met with a protective and supportive response (Ruggiero et al., 2004). In addition to the potential mental health benefits of support and protection by a caregiver, such a response could be expected to coincide with reduced risk of future assaults. Notably, Ruggiero et al. found that disclosure to mothers was unrelated to current PTSD in an adult sample of women victimized in childhood. Thus, disclosure to mothers appears to relate to PTSD risk only in the short term. Longitudinal research is needed to examine this pattern of findings more precisely. In this sample, disclosure to mothers also emerged as a significant correlate of $S A=D$ and delinquency risk at the bivariate level but did not remain associated with either variable in the final model.

Several study limitations deserve mention.

First, assessment was based on retrospective selfreport, which raises the potential for recall bias or misinterpretation. Second, although several steps were made to ensure that questions could 
be answered openly, it is likely that some withheld pertinent information. Third, use of a telephone interview excludes households (Census data estimate $5 \%$ ) without telephones. Fourth, we did not inquire about the context around sexual assault disclosures. Thus, we are unable to comment on the quality of the reactions provided by mothers and other potential confidants. It is likely that unassessed contextual factors would add explanatory power to our results. For example, a potential third-variable explanation involves the quality of mother-child relationships, which may relate to children's willingness to disclose assault soon after it occurs. This, in turn, could account for the relation between short-delay disclosure and psychosocial impairment. Research is needed to clarify these relations, as well as those involving other contextual variables that may play a role in decisions and timing around disclosure.

\section{IMPLICATIONS}

This study raises important issues for public policy and future research. For example, public awareness campaigns tend to focus primarily on the identification of child abuse victims and reduction of abuse risk. However, public education efforts tend not to address issues around sexual assault disclosure, such as the importance of protective and supportive caregiver reactions. To date, most public education efforts have taken the form of primary- and secondary-prevention protocols that are delivered to youth in the school system. A recent meta-analysis found that children who complete such programs tend show high levels of satisfaction and increased victimizationrelated knowledge and skills (Davis \& Gidycz, 2000). The content of prevention programs generally includes information designed to encourage disclosure to trusted adults. Such prevention programs also might benefit from the involvement of parents via supplemental education around providing supportive and protective responses to disclosure and to increase caregivers' identification skills around sexual assault in the event that victimized youth choose not to disclose. In addition, data are lacking regarding parental and parentchild relationship characteristics associated with child victims' likelihood of disclosing to nonoffending caregivers. Because research has found 
that parental support following disclosure is associated with healthier psychosocial outcomes and better response to treatment (e.g., Cohen \& Mannarino, 1998), such information could have potentially important implications for public policy and education.

\section{REFERENCES}

American Psychiatric Association. (1994). Diagnostic and statistical manual of mental disorders (4th ed.). Washington, DC: Author.

Cohen, J. A. \& Mannarino, A. P. (1998). Factors that mediate treatment outcome of sexually abused preschool children: Six- and 12-month follow-up. Journal of the American Academy of Child \& Adolescent Psychiatry, 37, 44-51.

Davis, M. K. \& Gidycz, C. A. (2000). Child sexual abuse prevention programs: A meta-analysis. Journal of Clinical Child Psychology, 29, 257-265.

Elliott, D., Huizinga, D., \& Ageton, S. S. (1985). Explaining delinquency and drug abuse. Thousand Oaks, CA: Sage.

Hanson, R. F., Kievit, L. W., Saunders, B. E., Smith, D. W., Kilpatrick, D. G., Resnick, H. S., et al. (2003). Correlates of adolescent reports of sexual assault: Findings from the national survey of adolescents. Child Maltreatment, 8, 261-272.

Hanson, R. F., Resnick, H. S., Saunders, B. E., Kilpatrick, D. G., $\&$ Best, C. (1999). Factors related to the reporting of childhood rape. Child Abuse \& Neglect, 23, 559-569.

Kilpatrick, D.G., Acierno, R. E., Resnick, H. S., Saunders, B. E., \& Best, C. L. (2000). Risk factors for adolescent substance abuse and dependence: Data from a national sample. Journal of Consulting \& Clinical Psychology, 68, 19-30.

Kilpatrick, D. G., Resnick, H. S., Freedy, J. R., Pelcovitz, D., Resick, P. A., Roth, S., et al. (1998). The posttraumatic stress disorder field trial: Evaluation of the PTSD construct: Criteria A through E. In T. Widiger et al. (Eds.), DSM-IV sourcebook (pp. 803-844). Washington, DC: American Psychiatric Press. 
Kilpatrick, D. G., Ruggiero, K. J., Acierno, R., Saunders, B. E., Resnick, H. S., \& Best, C. L. (2003). Violence and risk of PTSD, major depression, substance abuse=dependence, and comorbidity: Results from the National Survey of Adolescents. Journal of Consulting \& Clinical Psychology, 71, 692-700.

Kilpatrick, D. G., Resnick, H. S., Saunders, B. E., \& Best, C. L. (1989). The National Women's study PTSD module. Charleston: Department of Psychiatry and Behavioral Sciences, Medical University of South Carolina.

Ruggiero, K. J., Rheingold, A. A., Resnick, H. S., Kilpatrick, D. G., \& Galea, S. (in press). Comparison of two widely used PTSD-screening instruments: Implications for public mental health planning. Journal of Traumatic Stress.

Ruggiero, K. J., Saunders, B. E., Kilpatrick, D. G., Hedtke, K. A., Resnick, H. S., Hanson, R. F., et al. (2006). Has the sexual victimization of youth decreased in the U.S.? Results from the National Surveys of Adolescents. Manuscript in preparation.

Ruggiero, K. J., Smith, D. W., Hanson, R. F., Resnick, H. S., Saunders, B. E., Kilpatrick, D. G., et al. (2004). Is disclosure of childhood rape associated with mental health outcome? Results from the National Women's Study. Child Maltreatment, 9, 62-77.

Saunders, B. E., Kilpatrick,D. G., Hanson, R. F., Resnick, H. S., \&Walker, M. E. (1999). Prevalence, case characteristics, and long-term psychological correlates of child rape among women: A national survey. Child Maltreatment, 4, 187-200.

Smith, D.W., Letourneau, E., Saunders, B. E., Kilpatrick, D. G., Resnick, H. S., \& Best, C. L. (2000). Delay in disclosure of childhood rape: Results from a national survey. Child Abuse \& Neglect, 24, 273-287. 